\title{
Hypoplastic left heart syndrome: from the prenatal to the postnatal period
}

\author{
Anna Wojtowicz ${ }^{1}$, , Marek Raczka ${ }^{1}$, Zbigniew Kordon ${ }^{1}$, Agnieszka Ochoda-Mazur ${ }^{1}$,

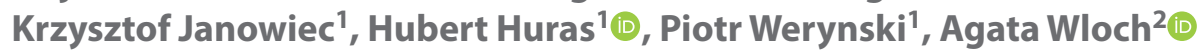 \\ ${ }^{1}$ Collegium Medicum, Jagiellonian University, Cracow, Poland \\ ${ }^{2}$ Department of Obstetrics and Gynecology in Ruda Slaska, Medical University of Silesia, Ruda Slaska, Poland
}

\begin{abstract}
Objectives: To analyse a population of foetuses with prenatally diagnosed hypoplastic left heart syndrome (HLHS).

Material and methods: Retrospective study of foetuses diagnosed with HLHS between 2013 and 2017 in a referral centre.

Results: HLHS was found in 9.7\% (65/665) of foetuses with cardiovascular abnormalities (CVA). As an isolated anomaly, HLHS was present in $40 \%$ of cases; in $24.5 \%$ other CVA were detected; in $14 \%$, CVA and extracardiac anomalies; and in $21.5 \%$ only extracardiac malformations. Genetic disorders were present in $18.4 \%(12 / 65)$ of foetuses. $42 \%$ of cardiovascular and $25 \%$ of extracardiac anomalies were diagnosed postnatally. There were 10 (15.4\%) elective terminations, 1 (1.5\%) spontaneous foetal demise. Two newborns died after birth before surgery. Of the 52 children who underwent Norwood surgery, 13 (25\%) died ( 9 with additional anomalies, and 4 with isolated HLHS). Of the 38 children who underwent stage II surgery, 2 (5.2\%) with isolated HLHS died, and 1 (2.6\%) with CVA.

Conclusions: A diagnosis of HLHS is an indication for a detailed examination of cardiac and noncardiac structures. It is advisable to consider genetic testing, together with the microarray assessment. The prognosis depends on underlying cardiac and extracardiac anomalies and coexisting genetic defects.
\end{abstract}

Key words: foetus; hypoplastic left heart syndrome; outcome; prenatal; postnatal

Ginekologia Polska 2021; 92, 4: 289-299

\section{INTRODUCTION}

The term hypoplastic left heart syndrome (HLHS) refers to a group of abnormalities characterized by severe underdevelopment of the left heart structures such as hypoplasia of the left ventricle (Fig.1) with mitral atresia or stenosis, aortic atresia or stenosis, and hypoplasia of the ascending aorta (Fig.2) [1].

HLHS is proportionately one of the most common congenital cardiac defects diagnosed prenatally [2]. A prenatal diagnosis of HLHS affords the opportunity for counselling and perinatal planning. To provide parents with the most accurate counselling, the advice should be based on current experience. There are some discrepancies about accompanying anomalies and survival. In several clinical and autopsy studies considering HLHS, extracardiac anomalies and/or genetic disorders that could affect the survival of infants were noted in up to $37 \%$ of the infants [3-5]. Before the era of surgical treatment, HLHS was responsible for approximately $30 \%$ of deaths in the first week of life for reasons related to the cardiovascular system and was the most frequent cause of death for neonates with heart defects $[6,7]$. Since the 1980s, when new surgical techniques were introduced, the prognosis for these patients has improved $[8,9]$, but the survival rates were lower in studies that included foetuses than in paediatric series $[4,10,11]$. However, most studies were conducted many years ago, and therefore, they may not reflect recent advances in the optimal management of infants with HLHS.

Therefore, the aim of this study was to present our experience with prenatally diagnosed HLHS to comprehensive analyse a population with HLHS, as well as the associated anomalies, neonatal outcomes and mortality rate in the first year of life.

\section{MATERIAL AND METHODS}

We retrospectively analysed cases of HLHS diagnosed during pregnancy between 2013 and 2017 in one Polish tertiary care referral centre for the prenatal diagnosis and management of foetal and neonatal pathology. We searched our computerized database for prenatally diagnosed HLHS, 


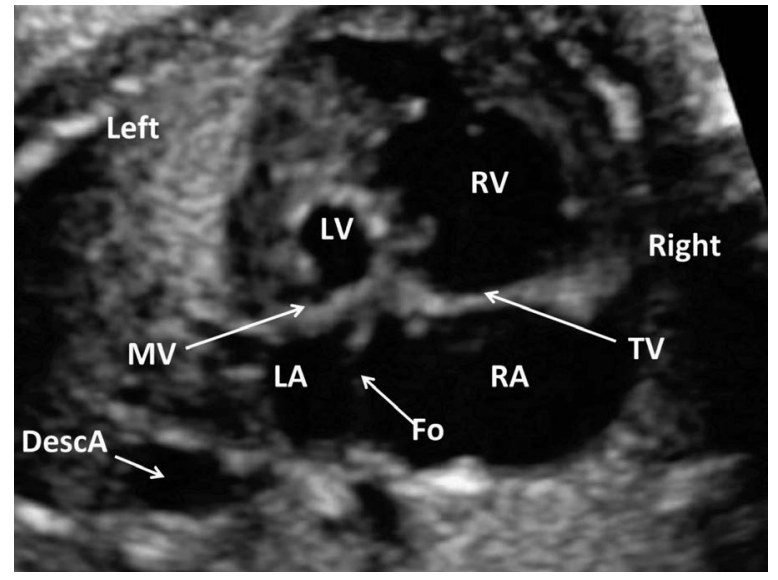

Figure 1. Four chamber view. Hypoplastic left ventricle with atretic mitral valve; DescA — descending aorta; Fo — foramen ovale; LA — left atrium; LV - left ventricle; MV — mitral valve; RA — right atrium; RV — right ventricle; TV — tricuspid valve

defined as hypoplasia of the left ventricle with aortic atresia or stenosis and with mitral atresia or stenosis between January 2013 and December 2017. In these cases, cardiac topology was normal with concordant atrioventricular and ventriculoarterial relationships. Patients with minor variants of hypoplastic left heart suitable for biventricular repair, as well as with borderline hypoplastic left ventricle, were excluded. We did not include cases with critical aortic stenosis who underwent foetal aortic balloon valvuloplasty in the study.

During this period, 3654 foetal screening examinations were performed in pregnant women at an increased risk of having a child with a cardiac defect. Ultrasound examinations were carried out using a Voluson E6 (GE Healthcare Medical Systems, Milwaukee, WI, USA) system and included a detailed assessment of cardiac and noncardiac structures according to the national guidelines [12-14] and the International Society of Ultrasound in Obstetrics and Gynaecology [15]. Foetal heart examinations were performed using conventional 2-dimensional ultrasound, as well as colour and pulsed-wave Doppler ultrasound, by cardiologists and physicians specialized in prenatal diagnoses and foetal echocardiography. Detected cases were recorded at the National Registry for Foetal Cardiac Pathology (www. orpkp.pl) and reviewed by supervisors from foetal cardiac centres [14].

The parents were counselled by a paediatric cardiologist and/or cardiac surgeon and received detailed information regarding the defect and available options. Cardiac transplantation was mentioned during post diagnosis counselling as a therapeutic option, but it was not offered as an option at our institution or in Poland. The option of compassionate care was also discussed, but none of the parents selected this option.

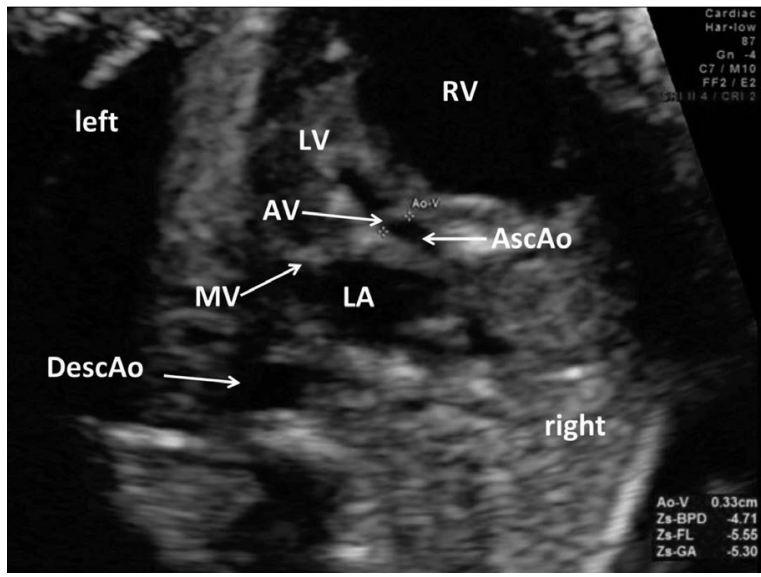

Figure 2. Left ventricle outflow tract with atretic aortic valve; AsAo — ascending aorta; AV — aortic valve; DescA — descending aorta; LA — left atrium; LV — left ventricle; MV — mitral valve; RV — right ventricle

The diagnoses of HLHS were confirmed by postnatal echocardiography, performed by experienced paediatric cardiologists, for live-born infants during their neonatal stay or based on autopsies for cases of stillbirth or termination. All patients were advised to undergo foetal karyotyping, including the exclusion of a 22q11.2 deletion and, since 2015 , the use of array comparative genomic hybridization (aCGH). Foetal invasive testing was recommended whenever extracardiac anomalies or high-risk clinical factors coexisted with HLHS. Isolated HLHS cases were defined if they were not accompanied by any other intracardiac or extracardiac anomalies reported prenatally or postnatally. We also assessed foramen ovale (FO) to be restrictive in utero when the maximum diameter measured in a four-chamber view was $\leq 3 \mathrm{~mm}$, with continuous high-velocity flow $>60 \mathrm{~cm} / \mathrm{s}$ $[16,17]$ and reverse flow in pulmonary veins [18]. Data collected from the electronic medical records included gestational age at diagnosis, sonographic findings, karyotype testing results, and pregnancy outcome. In addition, we analysed the indications for referral for examination and the results of first-trimester screening for aneuploidy. First-trimester screening was performed following the Foetal Medicine Foundation, UK recommendations (www.fetalmedicine.org) $[19,20]$. A nuchal translucency (NT) above the 95th percentile was considered abnormal. The long-term outcomes of the infants and children were determined. Postnatal follow-up for at least 12 months was available for 54 surviving patients (there was 1 loss to follow-up before stage II of surgery).

Data are described as the means and standard deviations or medians and ranges as appropriate. Categorical data are described as frequencies. Intergroup comparisons were made using the $\mathrm{x} 2$ test, and $\mathrm{p}<0.05$ was considered significant. 


\section{RESULTS \\ Incidence and characteristics of foetuses with a prenatal diagnosis of HLHS}

In a group of 665 foetuses with cardiovascular abnormalities diagnosed during the 5-year time period of the current study, HLHS was found in 65 (9.7\%) cases and was more common in a male than in female foetuses $(64.6 \%$ vs $35.4 \%)$. This corresponded to $1.8 \%(65 / 3654)$ of all foetal cardiac examinations performed during this period. All cases were diagnosed prenatally. During this time period, there was no case of HLHS that was diagnosed after birth at our institution. The average age of gravida was 29 years (Tab. 1), and in most cases, the pregnancy was low risk. Seven women were over 35 years old. For 32 women, the pregnancy was their first, and for 18 women, the pregnancy was high risk. Pregnancy loss was reported in 10 women, diabetes mellitus was reported in 2 women, and twin dichorionic pregnancies resulting from assisted reproductive technology were reported in 2 women. There was also 1 case of toxoplasmosis. For 54 (83\%) cases, the reason for echocardiography was an abnormal four-chamber view.

The mean gestational age at diagnosis was 19 weeks. A total of $22(33.8 \%)$ cases were detected in the first trimester, and $47(72 \%)$ cases were detected at $\leq 22$ weeks. First-trimester screening was performed for $51 / 65$ (78.4\%) cases, and a NT above the 95th percentile was noted in 14 foetuses (27.4\%). Tricuspid regurgitation was found in 7 (14\%) foetuses, a reverse a wave in the ductus venosus was found in $4(8 \%)$ foetuses, and all these foetuses had an abnormal karyotype. Additionally, in 2 (4\%) cases, there was ductus venosus agenesis.

Taking into account the anatomical type, the most common was aortic atresia with mitral valve stenosis or hypoplasia, making up $55 \%$ of cases (Tab. 1). Significant tricuspid regurgitation was found in $7(10.7 \%)$ cases. Restriction of the foramen ovale, which required balloon atrial septostomy after birth ( performed on average on the 4th day of life), was found in $4(7.4 \%)$ cases at a mean gestational age of 36 weeks, and all children survived until hospital discharge. An intact atrial septum was detected and confirmed postnatally in one (1.8\%) case at 16 weeks of gestation. In this case, balloon atrial septostomy was performed during the first five hours of life, but the infant died at 23 days of life after stage I surgery.

Foetal karyotyping was performed prenatally in 55 cases. In four cases, karyotyping was performed postnatally and was normal, and in three cases, karyotyping was performed post mortem because of dysmorphic features but showed a normal female karyotype. In three cases, the parents refused genetic testing, but detailed paediatric examinations after birth excluded the presence of any additional abnormalities. Chromosomal anomalies were detected in
12 (18.4\%) cases. Five foetuses had monosomy 45X0, two cases had a 22q11.2 microdeletion, 2 cases had trisomy 13 , two cases had trisomy 18, and one case had a 9p23deletion.

Among the 65 cases of HLHS, 26 (40\%) had isolated HLHS, and 39 (60\%) had associated anomalies.

Termination of pregnancy was chosen by 10 (15.4\%) families: chromosomal anomalies were present in 7 cases, and HLHS was isolated in 3 cases. The rest of the families at the time of prenatal counselling as well as after delivery stated that they preferred aggressive neonatal interventional care. There was 1 case of intrauterine foetal demise at 18 weeks of gestation. Among the 65 cases, 54 (83\%) live births were observed. The mean gestational age at delivery was 39 weeks, and preterm birth occurred in 2 cases. In 63\% of cases were delivered vaginally. Caesarean section was performed in 22 women; 8 cases had caesarean sections due to suspected intrauterine foetal asphyxia, and 14 cases had elective caesarean sections, including one case of intact atrial septum.

The average birth weight was $3346 \mathrm{~g}$. Four (7.4\%) foetuses were diagnosed with intrauterine growth restriction (IUGR), and another two (3.7\%) were small for gestational age (SGA).

On average, the neonates had an Apgar score of 9 at 1 minute, an oxygen saturation of $87.5 \%$ and a $\mathrm{pH}$ of 7.334 . Of the 54 live-born foetuses, two (3.7\%) died before treatment and were considered deaths for cardiac reasons. Thus, in our initial cohort of 65 foetuses, 52 (80\%) were admitted to the cardiac surgical centre with intention to treat on average on the 3rd day of life and underwent first-stage Norwood surgery on average on the 11 th day of life. Of these, 39 survived, and 13 died, leading to a Norwood operative survival rate of $75 \%$. There was 1 loss to follow-up. Of the 38 children who underwent stage II surgery, 3 (7.9\%) children died.

\section{Foetuses with isolated HLHS}

In 26 (40\%) cases, HLHS was the only abnormality diagnosed prenatally and confirmed postnatally. In this group, neither the prenatal karyotype analysis nor the postnatal assessment showed any chromosomal abnormalities.

On average, the diagnosis was made at 21 weeks of pregnancy. First-trimester screening was performed in $19 / 26(73.0 \%)$ cases, a NT above the $95^{\text {th }}$ percentile was noted in 4 foetuses (21.0\%), and tricuspid regurgitation was noted in 1 case. The diagnosis of HLHS was made during the first trimester in 7 cases (36.8\%), of which aortic stenosis with mitral stenosis was present in 3 cases, aortic atresia with mitral atresia was present in 2 cases and aortic atresia with mitral stenosis was present in 2 cases.

An isolated form of HLHS was assessed as a type with aortic atresia with mitral stenosis in $69.2 \%$ of cases, while both aortic atresia with mitral atresia and aortic stenosis with 
Table 1. Characteristics and outcomes of 65 foetuses with a prenatal diagnosis of hypoplastic left heart syndrome (HLHS)

\begin{tabular}{|c|c|c|c|}
\hline Characteristics & $\begin{array}{l}\text { Total } \\
n=65\end{array}$ & $\begin{array}{l}\text { Normal intracardiac and } \\
\text { extracardiac anatomy, } \\
n=26(40 \%)\end{array}$ & $\begin{array}{l}\text { Cardiovascular and extracardiac } \\
\text { anomalies, } \\
n=39(60 \%)\end{array}$ \\
\hline Maternal age, years $\pm S D$ (range) & $29.0 \pm 4.7(19-41)$ & $28.3 \pm 4.2(20-36)$ & $29.4 \pm 5.0(19-41)$ \\
\hline Gestational age at diagnosis, weeks \pm SD (range) & $19.4 \pm 6.4(12-34)$ & $21.4 \pm 7.3(12-34)$ & $17.8 \pm 5.0(12-28)^{*}$ \\
\hline Diagnosis $\leq 22$ weeks, $\mathrm{n}(\%)$ & $47(72.3)$ & $17(65.4)$ & $30(77.0)$ \\
\hline $\begin{array}{l}\text { First trimester screening, } \mathrm{n}(\%) \\
\text { Diagnosis in the first trimester, } \mathrm{n}(\%)\end{array}$ & $\begin{array}{l}51(78.4) \\
22(43.1)\end{array}$ & $\begin{array}{l}19(73.0) \\
7(36.8)\end{array}$ & $\begin{array}{l}32(82.0) \\
16(50.0)\end{array}$ \\
\hline Male, n (\%) & $44(67.7)$ & $20(76.9)$ & $22(56.4)$ \\
\hline $\begin{array}{l}\text { Abnormal karyotype, } n(\%) \text { : } \\
\text { - trisomy } 13, n \\
\text { - trisomy } 18, n \\
\text { - monosomy } 45, X 0, n \\
\text { - } 22 q 11.2 \text { microdeletion, } n \\
\text { - 9p23 deletion, } n\end{array}$ & $\begin{array}{l}12(18.4) \\
2 \\
2 \\
5 \\
2 \\
1\end{array}$ & $\begin{array}{l}0(0.0) \\
0 \\
0 \\
0 \\
0 \\
0\end{array}$ & $\begin{array}{l}12(30.7) \\
2 \\
2 \\
5 \\
2 \\
1\end{array}$ \\
\hline $\begin{array}{l}\text { Follow-up } \\
\text { - TOP, } n(\%) \\
\text { - IUFD, } n(\%) \\
\text { - Live birth, } n(\%) \\
\text { - Death before surgery, } n(\%) \\
\text { - Death after stage I surgery, } n(\%) \\
\text { - Death after stage Il surgery, } n(\%) \\
\text { - Lost to follow-up during the first year of life, } \\
n(\%)\end{array}$ & $\begin{array}{l}10(15.4) \\
1(1.5) \\
54(83.0) \\
2(3.7) \\
13(25.0) \\
3(7.7) \\
1(1.8)\end{array}$ & $\begin{array}{l}3(11.5) \\
0(0.0) \\
23(88.4) \\
1(4.3) \\
4(18.2) \\
2(11.1) \\
1(3.8)\end{array}$ & $\begin{array}{l}7(17.9) \\
1(3.1) \\
31(79.4) \\
1(3.2) \\
9(30.0) \\
1(4.7) \\
0(0.0)\end{array}$ \\
\hline Gestational age at birth, weeks \pm SD (range) & $39 \pm 1.0(36-42)$ & $39.3 \pm 1.0(38-41)$ & $39.0 \pm 1.3(36-42)$ \\
\hline Preterm birth, $\mathrm{n}(\%)$ & $2(3.7)$ & $0(0.0 \%)$ & $2(5.2)$ \\
\hline Birth weight, grams \pm SD (range) & $3346 \pm 545(2000-4350)$ & $3373 \pm 496(2300-4150)$ & $3327 \pm 594(2000-4350)$ \\
\hline $\begin{array}{l}\text { Mode of delivery: } \\
\text { - Caesarean section, } \mathrm{n}(\%) \\
\text { - Vaginal delivery, } \mathrm{n}(\%)\end{array}$ & $\begin{array}{l}22(40.0) \\
32(60.0)\end{array}$ & $\begin{array}{l}9(40.0) \\
14(60.0)\end{array}$ & $\begin{array}{l}13(42.0) \\
18(58.0)\end{array}$ \\
\hline $\begin{array}{l}\text { SGA, n (\%) } \\
\text { IUGR, n (\%) }\end{array}$ & $\begin{array}{l}2(3.7) \\
4(7.4)\end{array}$ & $\begin{array}{l}1(4.3) \\
1(4.3)\end{array}$ & $\begin{array}{l}1(3.2) \\
3(9.6)\end{array}$ \\
\hline $\begin{array}{l}\text { Apgar score } \\
1 \text { min, median (range) } \\
3 \text { min, median (range) } \\
5 \text { min, median (range) }\end{array}$ & $\begin{array}{l}9(5-10) \\
10(6-10) \\
10(4-10)\end{array}$ & $\begin{array}{l}9(5-10) \\
9.5(6-10) \\
9(8-10)\end{array}$ & $\begin{array}{l}9(8-10) \\
10(7-10) \\
10(4-10)\end{array}$ \\
\hline Saturation, n (\%) & $87.5 \pm 5.5$ & $88.4 \pm 3.2$ & $86.8 \pm 6.7$ \\
\hline $\mathrm{pH}, \mathrm{n}(\%)$ & $7.334 \pm 0.056$ & $7.322 \pm 0.067$ & $7.344 \pm 0.045$ \\
\hline $\begin{array}{l}\text { Anatomical type } \\
\text { MA/AA, n (\%) } \\
\text { MS/AS, n (\%) } \\
\text { MS/AA, n (\%) }\end{array}$ & $\begin{array}{l}15(23.0) \\
14(22.0) \\
36(55.0)\end{array}$ & $\begin{array}{l}4(15.4) \\
4(15.4) \\
18(69.2)\end{array}$ & $\begin{array}{l}11(28.4) \\
10(25.6) \\
18(46.0)\end{array}$ \\
\hline
\end{tabular}

${ }^{*} \mathrm{p}<0.05$; HLHS - hypoplastic left heart syndrome; SD — standard deviation; TOP — termination of pregnancy; IUFD — intrauterine foetal demise; IUGR — intrauterine growth restriction; $\mathrm{SGA}$ - small for gestational age; $\mathrm{MA}$ - mitral atresia; $\mathrm{MS}$ - mitral stenosis; $\mathrm{AA}$ - aortic atresia; $\mathrm{AS}$ - aortic stenosis

mitral stenosis occurred with the same frequency of $15.4 \%$. In this group, significant tricuspid regurgitation was noted in 2 cases, which was confirmed postnatally.

Termination of pregnancy was selected in 3 (11.5\%) cases and performed at $\leq 22$ weeks of pregnancy (the upper limit for termination in Poland). Among the 26 cases of isolated HLHS, 23 (88.5\%) were live births. Restriction of the foramen ovale, which required balloon atrial septostomy after birth, was found in 3 (13.0\%) foetuses. The mean gestational age at delivery was 39 weeks, and all pregnancies were at term. In $60 \%$ of cases, there was vaginal delivery. Caesarean section was performed in 9 women: 1 case had a caesarean section due to suspected intrauterine foetal asphyxia, and 8 cases had elective caesarean sections.

The average birth weight was $3373 \mathrm{~g}$. One (4.3\%) foetus was diagnosed with IUGR, and one (4.3\%) was SGA. On average, the neonates had an Apgar score of 9 at $1 \mathrm{~min}$ ute, an oxygen saturation of $88.4 \%$ and a pH of 7.322 .

One neonate with isolated HLHS died due to a heart block on the second day of life before surgery. Of the 22 chil- 


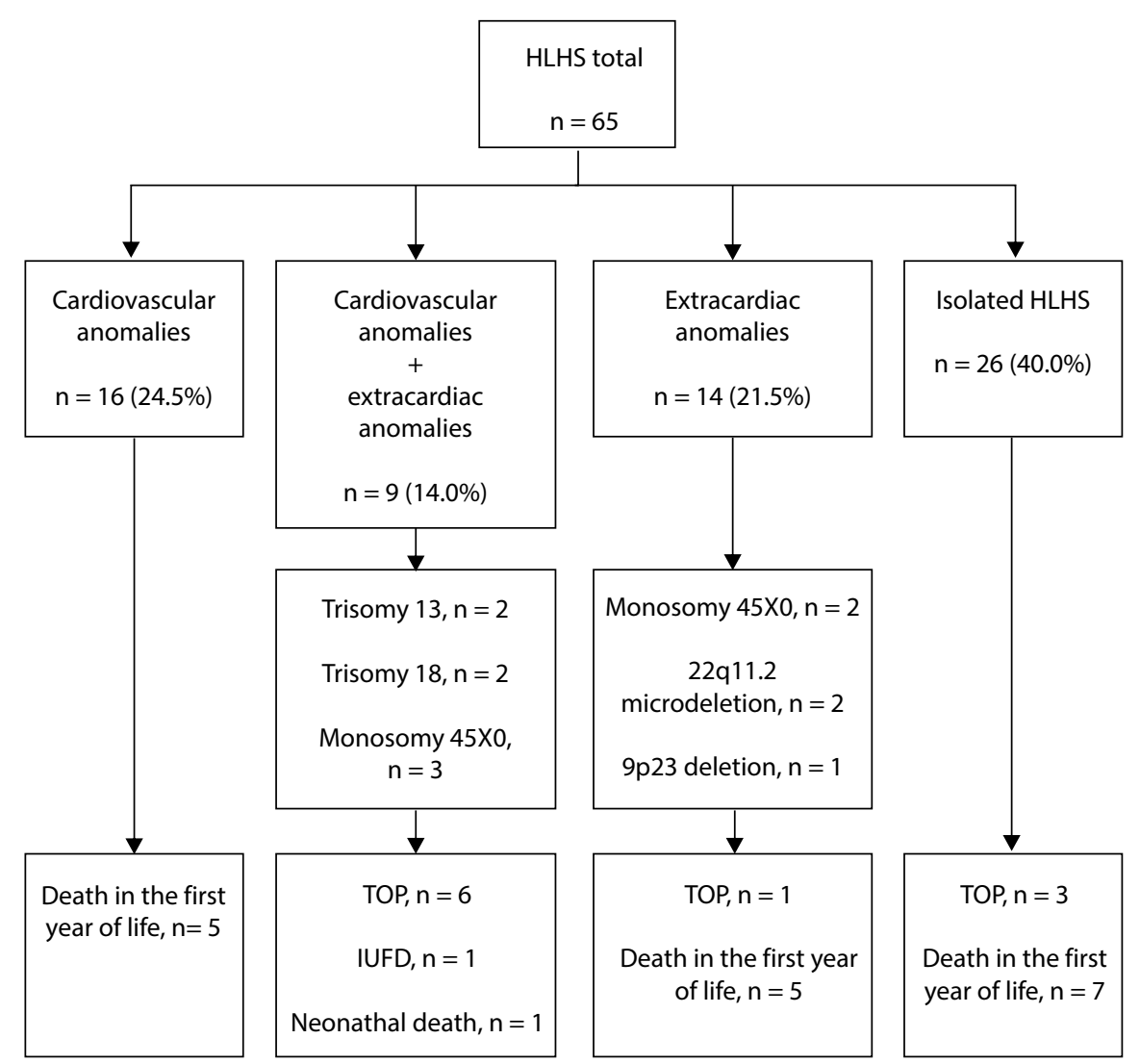

Figure 3. Hypoplastic left heart syndrome, associated conditions and outcomes of 65 foetuses; HLHS - hypoplastic left heart syndrome; IUFD - intrauterine foetal demise; TOP — termination of pregnancy

dren who underwent Norwood surgery, 4 (18\%) children died. There was 1 loss to follow-up, and among 17 children who underwent stage II surgery, 2 (11.7\%) died.

\section{Foetuses with cardiovascular and extracardiac anomalies}

In 39 cases of HLHS, additional anomalies were noted: 16 (41.0\%) had cardiovascular anomalies, 9 (23.0\%) had cardiovascular and extracardiac anomalies, and 14 (36.0\%) had only extracardiac anomalies (Fig. 1). Chromosomal anomalies were detected in 12 (30.7\%) cases, all of which had additional anomalies (Fig. 3). The most common heart defects were ventricular septal defects (VSDs), detected in 10 cases (40\%). In the other 2 cases, postnatal echocardiography revealed atrial septal defects (ASDs). One foetus had a right aortic arch and one partial abnormal venous return. The most common vascular anomaly was a single umbilical artery, which was present in $24 \%$ of cases. A persistent left superior vena cava was found in 4 foetuses, and during first-trimester screening, agenesis of ductus venosus was detected in 2 foetuses, which was confirmed in subsequent scans.

The most common extracardiac abnormalities were foetal hydrops, which was found in 6 cases, accompanied by chromosomal abnormalities (Turner syndrome in 5 cases and trisomy 18 in 1 case). Additionally, in 6 cases, craniofacial anomalies were present, and in 6 cases, central nervous system anomalies were present. Gastrointestinal defects and genitourinary defects were also found (Tab. 2). Three cases of facial dysmorphia as well as squinting, blindness, deafness, tubular disorder and cryptorchidism were detected postnatally, accounting for $25 \%$ of extracardiac anomalies. Furthermore, $42 \%$ of cardiovascular anomalies were diagnosed postnatally ( 8 cases of VSD, 2 cases of ASD and 1 case of partial anomalous pulmonary venous return) (Fig. 4).

HLHS in the group of foetuses with anomalies was detected earlier than in the group with isolated HLHS $(p=0.03)$ (Tab. 1).

First-trimester screening was performed in 32/39 (82.0\%) cases, and a NT above the 95th percentile was noted in 10 foetuses (31.2\%). Among the foetuses with increased NT, 8 had chromosomal abnormalities, and in 2 cases a normal karyotype; however, tubulopathy with blindness was detected postnatally in 1 case, and dysmorphic features were detected in 1 case. Tricuspid regurgitation was found in $6(18.7 \%)$ foetuses. A reverse wave in the ductus venosus was found in $4(8 \%)$ foetuses, and all these foetuses had an abnormal karyotype. Additionally, in 2 (4\%) cases, there was ductus venosus agenesis (Tab.3). 
Table 2. Types of abnormalities found in association with hypoplastic left heart syndrome (HLHS)

\begin{tabular}{|c|c|}
\hline Diagnosis & $n$ \\
\hline $\begin{array}{l}\text { Type of cardiovascular anomalies associated with HLHS, } \\
n=26 \\
\text { VSD } \\
\text { ASD } \\
\text { RAA } \\
\text { PAPVR } \\
\text { Persistent LVCS } \\
\text { SUA } \\
\text { Agenesis of DV } \\
\text { Total }\end{array}$ & $\begin{array}{l}10 \\
2 \\
1 \\
1 \\
4 \\
6 \\
2 \\
26\end{array}$ \\
\hline $\begin{array}{l}\text { Extracardiac anomalies, } \mathrm{n}=32 \\
\text { Thymus hypoplasia/aplasia } \\
\text { Craniofacial defects, } \mathrm{n}=6 \\
\text { - Dysmorphic features/facial dysmorphia } \\
\text { - Cleft lip and palate } \\
\text { - Micrognathia }\end{array}$ & $\begin{array}{l}3 \\
1 \\
2\end{array}$ \\
\hline $\begin{array}{l}\text { Skeletal defects, } n=3 \\
\text { - Clubfoot } \\
\text { - Polydactyly }\end{array}$ & $\begin{array}{l}1 \\
2\end{array}$ \\
\hline $\begin{array}{l}\text { Polyhydramnios } \\
\text { Hydrops } \\
\text { Squint }\end{array}$ & $\begin{array}{l}1 \\
6 \\
1\end{array}$ \\
\hline $\begin{array}{l}\text { CNS defects, } n=6 \\
\text { - Mega cisterna magna } \\
\text { - Blindness } \\
\text { - Deafness } \\
\text { - CCA } \\
\text { - Ventriculomegaly }\end{array}$ & $\begin{array}{l}2 \\
1 \\
1 \\
1 \\
1\end{array}$ \\
\hline $\begin{array}{l}\text { Gastrointestinal defects, } n=4 \\
\text { - Situs inversus } \\
\text { - Omphalocele } \\
\text { - Hepatomegaly with echogenic foci }\end{array}$ & $\begin{array}{l}2 \\
1 \\
1\end{array}$ \\
\hline $\begin{array}{l}\text { Genitourinary defects, } \mathrm{n}=3 \\
\text { - Hydronephrosis } \\
\text { - Tubular disorders } \\
\text { - Cryptorchidism } \\
\text { Total }\end{array}$ & $\begin{array}{l}1 \\
1 \\
1 \\
32\end{array}$ \\
\hline
\end{tabular}

ASD - atrial septal defect; CCA - corpus callosum agenesis; CNS - central nervous system; DV — ductus venosus; HLHS - hypoplastic left heart syndrome; LVCS - left vena cava superior; RAA — right aortic arch; SUA — single umbilical artery; VSD — ventricular septal defect; PAPVR — partial anomalous venous return

In the group of foetuses that underwent first-trimester screening for aneuploidy, the diagnosis of HLHS was made in $16(50.0 \%)$ cases.

Termination of pregnancy was selected in 7 (22.5\%) of the diagnosed 31 cases and performed at $\leq 22$ weeks of pregnancy, and all of these cases had an abnormal karyotype (trisomy 13 in 2 cases, trisomy 18 in 2 cases, and Turner syndrome in 3 cases). There was 1 intrauterine foetal demise at 18 weeks of gestation (a case with Turner syndrome and hydrops in one twin of a dichorionic pregnancy).
In the group of HLHS with additional anomalies, the type was assessed as aortic atresia with mitral hypoplasia in $46 \%$ of cases, aortic atresia with mitral atresia in $28.4 \%$ of cases and aortic stenosis with mitral hypoplasia in $25.6 \%$ of cases. In this group, significant tricuspid regurgitation was noted in 5 cases, which was confirmed postnatally. Restriction of the foramen ovale, which required balloon atrial septostomy after birth, was found in 2 foetuses. In one case, an intact atrial septum was detected and confirmed postnatally, and a persistent left vena cava superior was described. In this case, after elective caesarean section, balloon atrial septostomy was performed during the first five hours of life, but the infant died at 23 days of life after stage I surgery.

Among the 39 cases of HLHS with additional anomalies, 31 (79.5\%) were live born. The mean gestational age at delivery was 39 weeks. Two patients from the group with accompanying anomalies had a preterm birth at 36 weeks of gestation; one died at 12 days of life, and the second died at 64 days of life. In $58 \%$ of cases, there was vaginal delivery. Caesarean section was performed in 13 women; 7 cases had caesarean sections due to suspected intrauterine foetal asphyxia, and 6 cases, had elective caesarean sections.

The average birth weight was $3327 \mathrm{~g}$. Three (9.6\%) foetuses were diagnosed with IUGR, and the other foetus (3.2\%) was SGA. On average, the neonates had an Apgar score of 9 at 1 minute, an oxygen saturation of $86.8 \%$ and a $\mathrm{pH}$ of 7.344. One neonate died on the second day of life before surgery because of sudden cardiac arrest, and during prenatal scans, an enlarged liver with hyperechogenic foci was observed. Of the 30 children who underwent Norwood surgery, 9 (30\%) died, and among the 21 children who underwent stage II surgery, 1 (5.0\%) died (Fig. 5).

\section{DISCUSSION}

Our data show that HLHS is successfully diagnosed during the first half of pregnancy, especially in cases where additional anomalies are present.

Moreover, the prevalence of underlying genetic causes as well as cardiovascular and extracardiac anomalies associated with HLHS is substantial. It reinforces the already known, but often overlooked, fact that patients with HLHS frequently have other noncardiac and/or chromosomal abnormalities that likely affect the outcome. In this study of children with prenatal diagnoses, we also show a better survival rate after the first two stages of surgical treatment than previously reported.

In approximately $72 \%$ of cases, the diagnosis was made before the 22nd week of pregnancy, which is consistent with the observations of other authors [4]. The diagnosis of HLHS was made early, around the $17^{\text {th }}$ week, when associated anomalies were present, in contrast to cases of isolated 


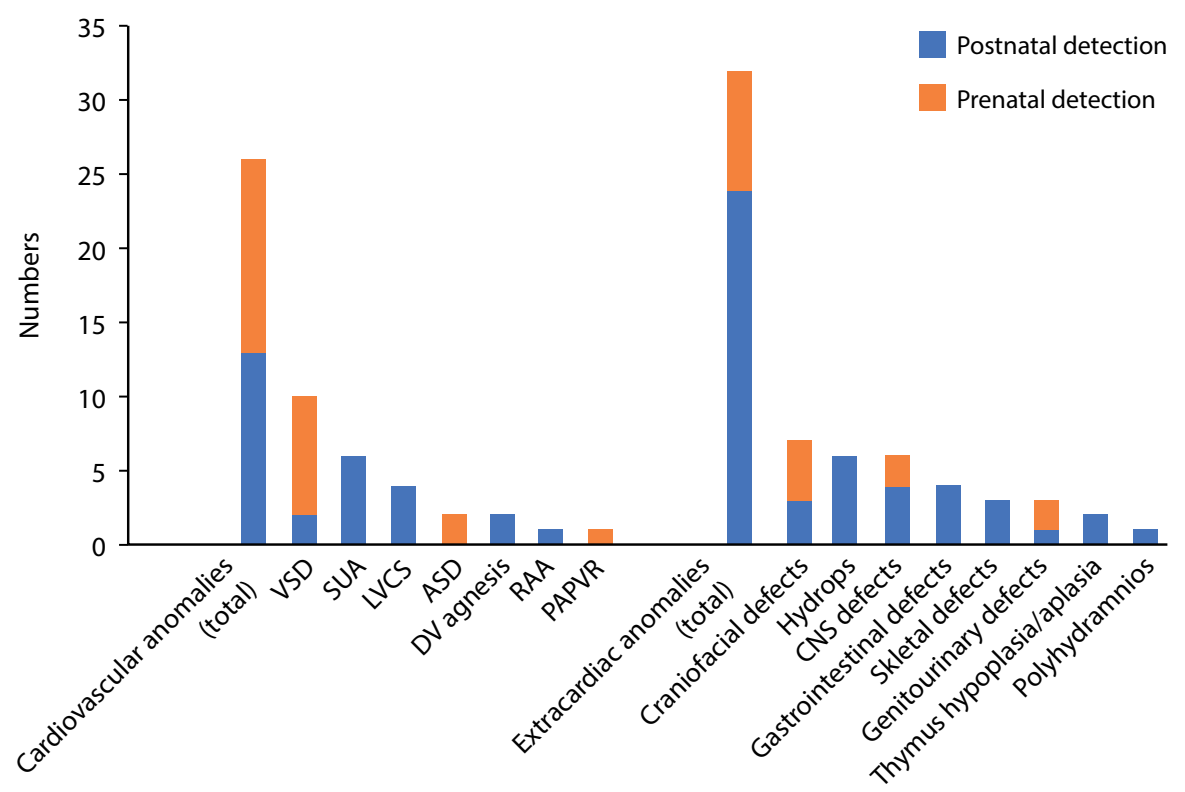

Figure 4. Hypoplastic left heart syndrome and associated anomalies detected prenatally and postnatally; ASD — atrial septal defect; CCA — corpus callosum agenesis; CNS - central nervous system; DV — ductus venosus; HLHS - hypoplastic left heart syndrome; LVCS - left vena cava superior; PAPVR — partial anomalous venous return; RAA — right aortic arch; SUA — single umbilical artery; VSD — ventricular septal defect

HLHS, where the diagnosis was made around 21 weeks of pregnancy. Interestingly, more than one-third of cases were diagnosed in the first trimester of pregnancy, and in the group with accompanying anomalies, as many as half of the cases that had undergone first-trimester screening were diagnosed with HLHS. Among the foetuses that were screened in the first trimester, the NT values in $27.4 \%$ of cases were above the 95 th percentile. An NT measurement above the 95th percentile for the crown-rump length is thought to be predictive of congenital heart disease, including conditions on the HLHS spectrum [20,21].

Early prenatal diagnosis has some important functions. First, it enables parents to be counselled in a timely and informed manner and to present information on prognosis and possible outcomes, including the option of elective termination of pregnancy. In our group, $15 \%$ of parents chose the termination option; this frequency is similar to that observed in the Rychik et al. study [22], where $11.7 \%$ of parents chose this option, but much lower than that reported in Europe (range 27-63\%) [4, 23-25]. This allows us an opportunity to analyse outcomes in a cohort for which there is a high rate of "intention-to-treat" patients.

A prenatal diagnosis of HLHS has been shown to result in improved preoperative haemodynamics [26-28], reduced comorbidity [29] and a better surgical outcome [22]. However, some studies have suggested a worse prognosis for antenatally diagnosed HLHS, with a survival rate of only $38 \%$ in one study [30] and an improved rate of $64.5 \%$ in a later cohort [31], while in the studies reported by paediatricians, the survival rate after surgical treatment was up to $90 \%[10,32]$.
In our study, the survival rate after the stage I stage Norwood operation was $75 \%$, which is lower than that in the study by Rychik et al. [22], where the survival rate was $83.8 \%$, but higher than that reported by other researchers [33]. Notably, the study by Rychik et al.[22] included variants of HLHS, namely, borderline hypoplastic left heart and atrioventricular septal defect.

The reasons for the worse prognosis are not clear, and this finding might indicate that the more severe spectrum of the disease is detected antenatally and that these babies would not have survived transfer to a specialist unit. Infants with an in utero diagnosis had a high frequency of complex risk factors, including prematurity, low birth weight, chromosomal anomalies, other extracardiac anomalies, additional intracardiac lesions, anatomical variants, and obstructed pulmonary venous return [34]. What is interesting, in our group FO restriction did not corresponded with higher mortality, what can be explained by the fact that it was not detected until 36 week of gestation. The study of Jadczak et al. [35] showed that earlier development and longer presence of FO restriction is associated with higher short-term mortality.

In our study, preterm delivery occurred in 2 cases, and these children died after stage I surgery. Growth disorders occurred in $6(11 \%)$ cases, and additional cardiovascular and extracardiac abnormalities were found in approximately $60 \%$ of cases. Notably, approximately $25 \%$ of extracardiac defects and $42 \%$ of cardiovascular defects were detected only after birth. The incidence of extracardiac abnormalities reported in the literature varies between $3 \%$ and $62 \%[3,34,36]$. 
Table 3. Characteristics of 39 foetuses with a prenatal diagnosis of hypoplastic left heart syndrome (HLHS) and associated anomalies

\begin{tabular}{|c|c|c|c|c|c|}
\hline Case & $\begin{array}{l}\text { GA at } \\
\text { diagnosis } \\
\text { (weeks) }\end{array}$ & NT & Associated anomalies & Karyotype & Perinatal outcome \\
\hline 1. & 23 & $1.9 \mathrm{~mm}$ & DV agenesis, VSD & $46, X Y$ & Live birth \\
\hline 2. & 19 & $1.2 \mathrm{~mm}$ & VSD & $46, X X$ & Live birth \\
\hline 3. & 20 & $2 \mathrm{~mm}$ & RAA & $46, X Y$ & Live birth \\
\hline 4. & 13 & $1.7 \mathrm{~mm}$ & VSD & $46, X X$ & Live birth \\
\hline 5. & 13 & $2.4 \mathrm{~mm}$ & hypoplastic nasal bone, VSD & $46, X Y$ & Live birth \\
\hline 6. & 25 & $1.4 \mathrm{~mm}$ & LVCS & $46, X X$ & Live birth \\
\hline 7. & 21 & $2.1 \mathrm{~mm}$ & LVCS & $46, X Y$ & Live birth \\
\hline 8. & 21 & $1.9 \mathrm{~mm}$ & VSD, PAPVR & $46, X Y$ & Live birth \\
\hline 9. & 13 & $1.5 \mathrm{~mm}$ & LVCS & $46, X Y$ & Live birth, death after stage I surgery \\
\hline 10. & 23 & $2.0 \mathrm{~mm}$ & VSD & $46, X Y$ & Live birth \\
\hline 11. & 21 & $1.8 \mathrm{~mm}$ & ASD, unroofed coronary sinus & $46, X X$ & Live birth \\
\hline 12. & 12 & $2.2 \mathrm{~mm}$ & SUA & $46, X Y$ & Live birth, death after stage I surgery \\
\hline 13. & 26 & $2 \mathrm{~mm}$ & LVCS, RVCS agenesis, IUGR & $46, X Y$ & Live birth, death after stage I surgery \\
\hline 14. & 21 & $1.6 \mathrm{~mm}$ & VSD & $46, X Y$ & Live birth, death after stage I surgery \\
\hline 15. & 23 & $1.3 \mathrm{~mm}$ & VSD & $46, \mathrm{XX}$ & Live birth, death after stage II surgery \\
\hline 16. & 19 & $1.8 \mathrm{~mm} ; \mathrm{TR}$ & ASD, TR & $46, X Y$ & Live birth \\
\hline 17. & 12 & $3.3 \mathrm{~mm}$; & SUA, reverse a wave in DV, polydactyly & $47, X Y,+13$ & TOP \\
\hline 18. & 13 & $9.6 \mathrm{~mm}$ & $\begin{array}{l}\text { One twin in dichorionic diamniotic } \\
\text { pregnancy, hydrops }\end{array}$ & $45 \times 0$ & IUFD (18 weeks) \\
\hline 19. & 13 & $2.8 \mathrm{~mm}$ & SUA, TR, micrognathia & $47, X Y,+18$ & TOP \\
\hline 20. & 19 & $2.3 \mathrm{~mm}$ & VSD, deafness & $46, X X$ & Live birth \\
\hline 21. & 12 & $7.2 \mathrm{~mm}$ & $\begin{array}{l}\text { Hydrops, omphalocele, hyperechogenic } \\
\text { bowels, SUA }\end{array}$ & $47, X X,+18$ & TOP \\
\hline 22. & 12 & $12 \mathrm{~mm}$ & Hydrops, SUA & $45 \times 0$ & TOP \\
\hline 23. & 13 & $2.9 \mathrm{~mm}$ & SUA & $47, X Y,+13$ & TOP \\
\hline 24. & 12 & $11.2 \mathrm{~mm}$ & Hydrops in first trimester, SUA & $45 \times 0$ & TOP \\
\hline 25. & 28 & not done & VSD, CCA, facial dysmorphia & $46, X X$, dysmorphy & Live birth, death after stage I surgery \\
\hline 26. & 21 & $2.1 \mathrm{~mm}$ & Cryptorchidism & $46, X Y$ & Live birth \\
\hline 27. & 27 & not done & Thymus aplasia, squint & $\begin{array}{l}46, \mathrm{XY}, 22 \mathrm{q} 11.2 \\
\text { microdeletion }\end{array}$ & Live birth \\
\hline 28. & 12 & $3.2 \mathrm{~mm}$ & $\begin{array}{l}\text { Mega cisterna magna, facial dysmorphia, } \\
\text { shortening of long bones, SGA }\end{array}$ & $46, X X$ & Live birth, death after stage I surgery \\
\hline 29. & 12 & $2 \mathrm{~mm}$ & TR, hydronephrosis & $46, X Y$ & Live birth \\
\hline 30. & 13 & $4.5 \mathrm{~mm}$ & Hydrops & $45 \times 0$ & TOP \\
\hline 31. & 25 & not done & Situs inversus & $46, X X$ & Live birth \\
\hline 32. & 19 & not done & Club foot & $46, X Y$ & Live birth, death after stage I surgery \\
\hline 33. & 21 & $1.7 \mathrm{~mm}$ & Facial dysmorphia, IUGR & $46, X X$ dysmorphia & Live birth, death after stage I surgery \\
\hline 34. & 18 & not done & $\begin{array}{l}\text { Polyhydramnios, facial dysmorphia, } \\
\text { thymic aplasia }\end{array}$ & $\begin{array}{l}46, X X \\
22 q 11.2 \text { microdeletion }\end{array}$ & Live birth \\
\hline 35. & 20 & not done & Enlarged liver with hyperechogenic foci & $46, X Y$ & Live birth, death on day 2 \\
\hline 36. & 12 & $6 \mathrm{~mm}$ & Hydrops 1tr & $45 \times 0$ & Live birth \\
\hline 37 & 20 & not done & $\begin{array}{l}\text { IUGR, mega cisterna magna, } \\
\text { ventriculomegaly }\end{array}$ & $\begin{array}{l}46, X X \text {, deletion in the } \\
\text { region } 9 p 23\end{array}$ & Live birth, death after stage I surgery \\
\hline 38. & 12 & $3.5 \mathrm{~mm}$ & Tubular disorder, blindness & $46, X Y$ & Live birth \\
\hline 39. & 18 & $1.8 \mathrm{~mm}$ & Situs inversus & $46, X Y$ & Live birth \\
\hline
\end{tabular}

ASD - atrial septal defect; CCA — corpus callosum agenesis; DV — ductus venosus; GA - gestational age; HLHS - hypoplastic left heart syndrome; IUFD — intrauterine foetal demise (stillbirth); IUGR - intrauterine growth restriction; LVCS - left vena cava superior; NT — nuchal translucency; PAPVR — partial anomalous pulmonary venous return; RAA — right aortic arch; RVCS — right vena cava superior; SGA — small for gestational age; SUA — single umbilical artery; TR — tricuspid regurgitation; TOP - termination of pregnancy; VSD - ventricular septal defect 


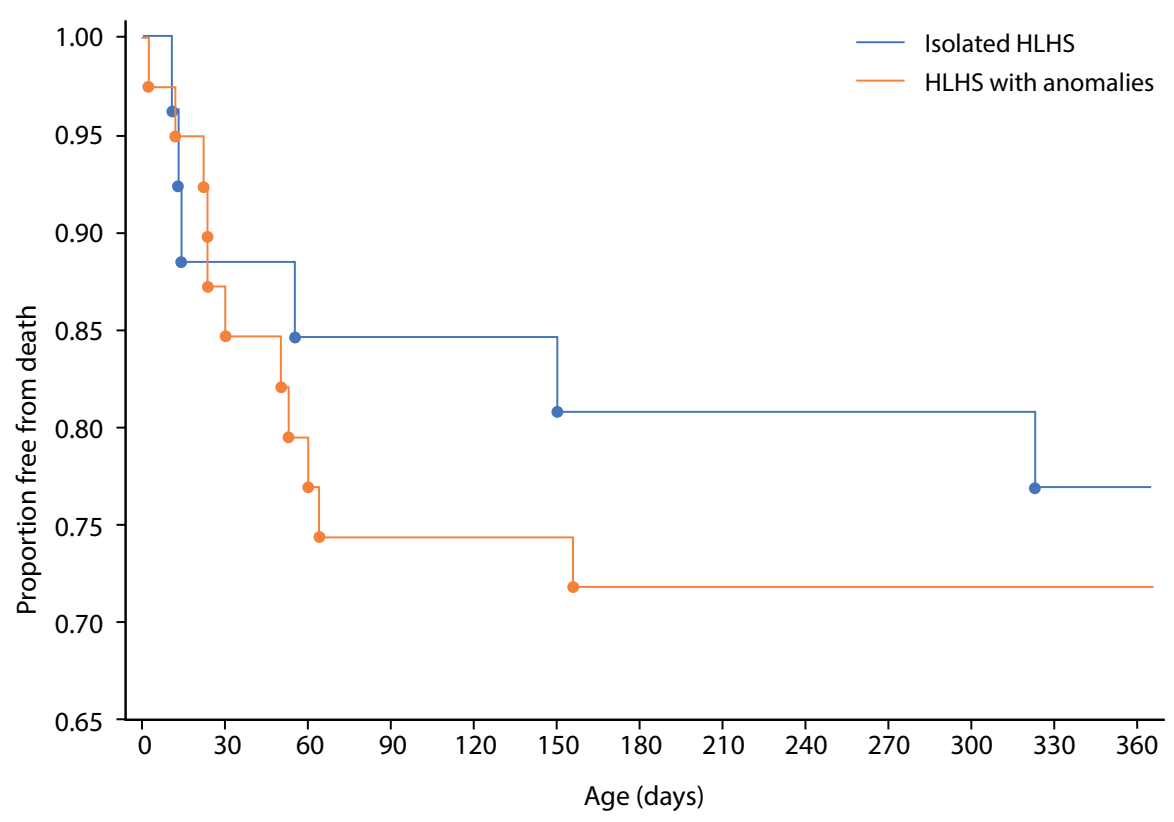

Figure 5. Kaplan Meier curve of survival to 360 days since birth after prenatal diagnosis of isolated hypoplastic left heart syndrome and hypoplastic left heart syndrome with associated anomalies

Such a wide variation in the frequency of additional defects may result from differences in the adapted definition of left hypoplasia syndrome as well as differences between the studied populations.

In a multicentre study, Song et al. [5] reported that isolated HLHS occurred in $62.8 \%$ of cases. However, in the study by Tennstedt et al. [37], only $38 \%$ of foetuses examined by autopsy were found to have isolated HLHS, which is consistent with our observations, where isolated HLHS occurred in $40 \%$ of cases.

The improvement in survival may reflect the fact that more anomalies associated with HLHS are now being noticed. Previous studies were based largely on findings by autopsy, in the context of which it was certainly difficult to detect the hearing and eye defects that were detected after birth in the patients included in our study.

Additionally, in the present study, genetic disorders were noted in $18 \%$ of cases, which is consistent with previous studies [3, 30, 34, 38]. Moreover Jansen et al. [39] showed that in left-sided congenital heart defects that appear isolated, with normal chromosome analysis and 22q11.2 FISH analysis, array analysis detected clinically significant copy number variants. All the abnormal karyotypes in our study were associated with additional cardiovascular and extracardiac structural anomalies. This is similar to observation by other studies that showed that in foetuses with isolated heart lesions, the rate of abnormal chromosomes with no anomalies on sonography was much lower than that when other anomalies were present [37].
Therefore, we suggest that all patients with HLHS should be thoroughly evaluated and undergo cytogenetic testing. Parents should also be informed that some defects can be detected only after birth.

There are several limitations to our retrospective study. First, we conducted an institutional, rather than a population-based, study that encompassed a small number of foetuses with HLHS. Our hospital provides excellent health care, including a neonatal oximetry screening programme. Conversely, as a tertiary care referral centre, our rate of associated anomalies may be overestimated because we care for higher-risk patients.

\section{CONCLUSIONS}

In summary, HLHS is currently diagnosed during the first half of pregnancy, giving parents the opportunity to decide the future of the pregnancy. A diagnosis of HLHS is also an indication for a detailed assessment of foetal anatomy, as the percentage of accompanying cardiovascular and noncardiac defects is significant. It is advisable to consider genetic testing, together with a microarray assessment, especially in cases of accompanying defects. It should also be noted that some of the anomalies can be detected only after birth. The survival rate of the foetal group after prenatal diagnosis after the first two stages of surgery is similar to those reported in paediatric analyses, but in the case of accompanying anomalies, the prognosis is poor.

\section{Acknowledgments}

None 


\section{Statement of Ethics}

The institutional review board considered ethical approval for this analysis to be unnecessary since the sonographic evaluations were performed as an integral part of routine clinical visits to the ultrasound departments, for which informed consent had been obtained from the women. The scans were anonymized.

\section{Conflict of interest}

The authors have no conflicts of interest to declare.

\section{Funding Sources}

This research did not receive any specific grant from funding agencies in the public, commercial, or not-for-profit sectors.

\section{REFERENCES}

1. Simpson JM. Hypoplastic left heart syndrome. Ultrasound Obstet Gynecol. 2000; 5: 271-278.

2. van Velzen $\mathrm{CL}$, Clur SA, Rijlaarsdam MEB, et al. Prenatal detection of congenital heart disease--results of a national screening programme. BJOG. 2016; 123(3): 400-407, doi: 10.1111/1471-0528.13274, indexed in Pubmed: 25625301.

3. Natowicz M, Chatten J, Clancy R, et al. Genetic disorders and major extracardiac anomalies associated with the hypoplastic left heart syndrome. Pediatrics. 1988; 82(5): 698-706, indexed in Pubmed: 3186348.

4. Galindo A, Nieto O, Villagrá S, et al. Hypoplastic left heart syndrome diagnosed in fetal life: associated findings, pregnancy outcome and results of palliative surgery. Ultrasound Obstet Gynecol. 2009; 33(5): 560-566, doi: 10.1002/uog.6355, indexed in Pubmed: 19367583.

5. Song MS, Hu A, Dyamenahalli U, et al. Extracardiac lesions and chromosomal abnormalities associated with major fetal heart defects: comparison of intrauterine, postnatal and postmortem diagnoses. Ultrasound Obstet Gynecol. 2009; 33(5): 552-559, doi: 10.1002/uog.6309, indexed in Pubmed: 19350566.

6. Lambert EC, Canent RV, Hohn AR. Congenital cardiac anomalies in the newborn. A review of conditions causing death or severe distress in the first month of life. Pediatrics. 1966; 37(2): 343-351, indexed in Pubmed: 5902095.

7. Gillum RF. Epidemiology of congenital heart disease in the United States. Am Heart J. 1994; 127(4 Pt 1): 919-927, doi: 10.1016/00028703(94)90562-2, indexed in Pubmed: 8154432.

8. Breymann T, Kirchner G, Blanz U, et al. Results after Norwood procedure and subsequent cavopulmonary anastomoses for typical hypoplastic left heart syndrome and similar complex cardiovascular malformations. Eur J Cardiothorac Surg. 1999; 16(2): 117-124, doi: 10.1016/s10107940(99)00155-4, indexed in Pubmed: 10485407.

9. Mahle WT, Spray TL, Wernovsky G, et al. Survival after reconstructive surgery for hypoplastic left heart syndrome: A 15-year experience from a single institution. Circulation. 2000; 102(19 Suppl 3): III136-III141, doi: 10.1161/01.cir.102.suppl_3.iii-136, indexed in Pubmed: 11082376.

10. Azakie T, Merklinger SL, McCrindle BW, et al. Evolving strategies and improving outcomes of the modified norwood procedure: a 10-year single-institution experience. Ann Thorac Surg. 2001; 72(4): 1349-1353, doi: 10.1016/s0003-4975(01)02795-3, indexed in Pubmed: 11603459.

11. Pigula FA, Vida V, Del Nido $P$, et al. Contemporary results and current strategies in the management of hypoplastic left heart syndrome. Semin Thorac Cardiovasc Surg. 2007; 19(3): 238-244, doi: 10.1053/j. semtcvs.2007.07.002, indexed in Pubmed: 17983951.

12. Słodki M, Respondek-Liberska M. [Proposal of screening fetal heart examination form granted by Polish Ministry of Health Program Kardio-Prenatal 2008]. Ginekol Pol. 2009; 80(6): 466-470, indexed in Pubmed: 19642607.

13. Sekcja Ultrasonografii Polskiego Towarzystwa Ginekologicznego. [Polish Gynecological Society--Ultrasound Section Guidelines on ultrasound screening in uncomplicated pregnancy (2 December 2011)]. Ginekol Pol. 2012; 83(4): 309-315, indexed in Pubmed: 22712266.
14. Slodki M, Szymkiewicz-Dangel J, Tobota Z, et al. The Polish National Registry for Fetal Cardiac Pathology: organization, diagnoses, management, educational aspects and telemedicine endeavors. Prenat Diagn. 2012; 32(5): 456-460, doi: 10.1002/pd.3838, indexed in Pubmed: 22495926.

15. Carvalho JS, Allan LD, Chaoui R, et al. ISUOG Practice Guidelines (updated): sonographic screening examination of the fetal heart. Ultrasound Obstet Gynecol. 2013; 41(3): 348-359, doi: 10.1002/uog.12403, indexed in Pubmed: 23460196.

16. Kiserud T, Rasmussen S. Ultrasound assessment of the fetal foramen ovale. Ultrasound Obstet Gynecol. 2001; 17(2): 119-124, doi: 10.1046/j. 1469-0705.2001.00331.x, indexed in Pubmed: 11251919.

17. Taketazu M, Barrea C, Smallhorn JF, et al. Intrauterine pulmonary venous flow and restrictive foramen ovale in fetal hypoplastic left heart syndrome. J Am Coll Cardiol. 2004; 43(10): 1902-1907, doi: 10.1016/j. jacc.2004.01.033, indexed in Pubmed: 15145119.

18. Chintala K, Tian Z, Du W, et al. Fetal pulmonary venous Doppler patterns in hypoplastic left heart syndrome: relationship to atrial septal restriction. Heart. 2008; 94(11): 1446-1449, doi: 10.1136/hrt.2007.123497, indexed in Pubmed: 17923465.

19. Pandya PP, Snijders RJ, Johnson SP, et al. Screening for fetal trisomies by maternal age and fetal nuchal translucency thickness at 10 to 14 weeks of gestation. Br J Obstet Gynaecol. 1995; 102(12): 957-962, doi: 10.1111/j.1471-0528.1995.tb10902.x, indexed in Pubmed: 8652486.

20. Hyett J, Perdu M, Sharland G, et al. Using fetal nuchal translucency to screen for major congenital cardiac defects at 10-14 weeks of gestation: population based cohort study. BMJ. 1999; 318(7176): 81-85, doi: 10.1136/bmj.318.7176.81, indexed in Pubmed: 9880278.

21. Atzei A, Gajewska K, Huggon IC, et al. Relationship between nuchal translucency thickness and prevalence of major cardiac defects in fetuses with normal karyotype. Ultrasound Obstet Gynecol. 2005; 26(2): 154-157, doi: 10.1002/uog.1936, indexed in Pubmed: 15977311.

22. Rychik J, Szwast A, Natarajan S, et al. Perinatal and early surgical outcome for the fetus with hypoplastic left heart syndrome: a 5-year single institutional experience. Ultrasound Obstet Gynecol. 2010; 36(4): 465-470, doi: 10.1002/uog.7674, indexed in Pubmed: 20499409.

23. McElhinney DB, Marshall AC, Wilkins-Haug LE, et al. Improved surgical outcome after fetal diagnosis of hypoplastic left heart syndrome. Circulation. 2001; 103(9): 1269-1273, doi: 10.1161/01.cir.103.9.1269, indexed in Pubmed: 11238272.

24. Weber RW, Stiasny B, Ruecker B, et al. Prenatal Diagnosis of Single Ventricle Physiology Impacts on Cardiac Morbidity and Mortality. Pediatr Cardiol. 2019; 40(1): 61-70, doi: 10.1007/s00246-018-1961-1, indexed in Pubmed: 30121866.

25. Marek J, Tomek V, Skovránek J, et al. Prenatal ultrasound screening of congenital heart disease in an unselected national population: a 21 -year experience. Heart. 2011; 97(2): 124-130, doi: 10.1136/hrt.2010.206623, indexed in Pubmed: 21163892

26. Verheijen PM, Lisowski LA, Stoutenbeek $P$, et al. Prenatal diagnosis of congenital heart disease affects preoperative acidosis in the newborn patient. J Thorac Cardiovasc Surg. 2001; 121(4): 798-803, doi: 10.1067/mtc.2001.112825, indexed in Pubmed: 11279423.

27. Pruetz JD, Carroll C, Trento LU, et al. Outcomes of critical congenital heart disease requiring emergent neonatal cardiac intervention. Prenat Diagn. 2014; 34(12): 1127-1132, doi: 10.1002/pd.4438, indexed in Pubmed: 24947130.

28. Thakur V, Munk N, Mertens L, et al. Does prenatal diagnosis of hypoplastic left heart syndrome make a difference? - A systematic review. Prenat Diagn. 2016; 36(9): 854-863, doi: 10.1002/pd.4873, indexed in Pubmed: 27416335.

29. Mahle WT, Clancy RR, McGaurn SP, et al. Impact of prenatal diagnosis on survival and early neurologic morbidity in neonates with the hypoplastic left heart syndrome. Pediatrics. 2001; 107(6): 1277-1282, doi: 10.1542/peds.107.6.1277, indexed in Pubmed: 11389243.

30. Brackley KJ, Kilby MD, Wright JG, et al. Outcome after prenatal diagnosis of hypoplastic left-heart syndrome: a case series. Lancet. 2000; 356(9236): 1143-1147, doi: 10.1016/s0140-6736(00)02756-2, indexed in Pubmed: 11030293.

31. Rasiah SV, Ewer AK, Miller P, et al. Antenatal perspective of hypoplastic left heart syndrome: 5 years on. Arch Dis Child Fetal Neonatal Ed. 2008; 93(3): F192-F197, doi: 10.1136/adc.2006.112482, indexed in Pubmed: 18006564. 
32. Tweddell JS, Hoffman GM, Mussatto KA, et al. Improved survival of patients undergoing palliation of hypoplastic left heart syndrome: lessons learned from 115 consecutive patients. Circulation. 2002; 106(12 Suppl 1): 182-189, indexed in Pubmed: 12354714

33. Hehir DA, Dominguez TE, Ballweg JA, et al. Risk factors for interstage death after stage 1 reconstruction of hypoplastic left heart syndrome and variants. J Thorac Cardiovasc Surg. 2008; 136(1): 94-9, 99.e1, doi: 10.1016/j.jtcvs.2007.12.012, indexed in Pubmed: 18603060.

34. Allan LD, Apfel HD, Printz BF. Outcome after prenatal diagnosis of the hypoplastic left heart syndrome. Heart. 1998; 79(4): 371-373, doi: 10.1136/hrt.79.4.371, indexed in Pubmed: 9616345.

35. Jadczak A, Respondek-Liberska M, Sokołowski $Ł$, et al. International Prenatal Cardiology Collaboration Group. Hypoplastic left heart syndrome with prenatally diagnosed foramen ovale restriction: diagnosis, management and outcome. J Matern Fetal Neonatal Med. 2020 [Epub ahead of print]: 1-8, doi: 10.1080/14767058.2020.1716717, indexed in Pubmed: 31986935.
36. Verheijen PM, Lisowski LA, Plantinga RF, et al. Prenatal diagnosis of the fetus with hypoplastic left heart syndrome management and outcome. Herz. 2003; 28(3): 250-256, doi: 10.1007/s00059-003-2439-2, indexed in Pubmed: 12756482

37. Tennstedt $\mathrm{C}$, Chaoui R, Körner $\mathrm{H}$, et al. Spectrum of congenital heart defects and extracardiac malformations associated with chromosomal abnormalities: results of a seven year necropsy study. Heart. 1999; 82(1): 34-39, doi: 10.1136/hrt.82.1.34, indexed in Pubmed: 10377306.

38. Reis PM, Punch MR, Bove EL, et al. Obstetric management of 219 infants with hypoplastic left heart syndrome. Am J Obstet Gynecol. 1998; 179(5): 1150-1154, doi: 10.1016/s0002-9378(98)70123-1, indexed in Pubmed: 9822492.

39. Jansen FAR, Hoffer MJV, van Velzen CL, et al. Chromosomal abnormalities and copy number variations in fetal left-sided congenital heart defects. Prenat Diagn. 2016; 36(2): 177-185, doi: 10.1002/pd.4767, indexed in Pubmed: 26716421. 